\title{
Molecular Mobility of Hydroxyethyl Cellulose (HEC) Films Characterised by Thermally Stimulated Currents (TSC) Spectroscopy
}

Samuel K. Owusu-Ware, Joshua Boateng, Daniel Jordan, Sara Portefaix, Renata Tasseto,

Camila D. Ramano, Milan D. Antonijević.

Faculty of Engineering and Science, University of Greenwich (Medway Campus), Chatham Maritime, Kent ME4 4TB, UK.

Corresponding Authors:

Samuel K. Owusu-Ware

E-mail: Samuel.K.Owusu-Ware@gre.ac.uk

Milan D. Antonijević

E-mail: M.Antonijevic@greenwich.ac.uk

Tel: $+44(0) 2083319841$

Fax: +44(0)20 83319805

Key words: Molecular mobility, Hydroxyethyl cellulose (HEC), Polymeric films, Thermally stimulated current (TSC), Tensile properties

\section{(ABSTRACT)}

Molecular mobility has long been established to relate to textural properties and stability of polymer films and is therefore an important property to characterise to better understand pharmaceutical film formulations. The molecular mobility of solvent cast hydroxyethyl cellulose (HEC) films has been investigated by means of thermally stimulated current (TSC) 
(C) 2016 This manuscript version is made available under the CC-BY-NC-ND 4.0 license http://creativecommons.org/licenses/by-nc-nd/4.0/

below the temperature at which the film was formed. Preliminary physical characterisation of the films was performed using XRPD, TGA, DSC and texture analysis (tensile properties). XRPD results showed the films to be completely amorphous with $T_{g}$ determined by DSC to be $127 \pm 1^{\circ} \mathrm{C}$. TGA analysis showed the films to contain $8 \pm 1 \%$ water and film was dried to only $0.06 \pm 0.01 \%$ water content when heated to $160^{\circ} \mathrm{C}$. Application of TSC detected molecular mobility in HEC films at sub-zero temperatures. Two motional transitions with average relaxation time of $50 \pm 3 \mathrm{~s}$ were identified; a $\beta$-relaxation at $-57 \pm 2^{\circ} \mathrm{C}$, attributed to localised non-cooperative orientation of HEC polymer chain ends and the hydroxyethyl side groups and an $\alpha$-relaxation, originating from cooperative segmental mobility, at $-20 \pm 2{ }^{\circ} \mathrm{C}$. The tensile properties i.e. elongation, tensile strength and elastic modulus of the HEC film have been related to the molecular relaxation processes detected by TSC.

\section{Introduction}

Polymer films are one of the most important technologies in pharmaceutical development with applications ranging from use as drug delivery systems such as Triaminic and Theraflu thin strips (Novartis), and use in controlled drug delivery such as films in enteric coated tablets to enhancing the appearance and taste of pharmaceutical products (Felton, 2007, Bhattacharjya and Wurster, 2008, Bala et al., 2013). Optimisation of these films for a particular application, however, is a challenging process and one that requires in-depth understanding of materials behaviour. It is established that mechanical (tensile) properties and stability, which are commonly characterised to evaluate formulated films, are associated with the glass transition temperature $\left(T_{g}\right)$ (Fadda et al., 2010, Connie and John, 2005, McPhillips et al., 1999). The $T_{g}$ (in addition to the mechanical properties and the physical and chemical stability) of polymer films have, in turn, been related to molecular mobility (Damaceanu et al., 2014, Ballesteros and Walters, 2011, Fadda et al., 2010, Bhugra et al., 2008, Zhang et al., 2013). Characterisation 
(C) 2016 This manuscript version is made available under the CC-BY-NC-ND 4.0 license http://creativecommons.org/licenses/by-nc-nd/4.0/

of molecular mobility is therefore important to better understand polymer film performance for pharmaceutical applications.

Various analytical techniques have been employed to investigate molecular dynamics in polymer films. Techniques such as de-wetting (Connie and John, 2005, Wang and McKenna, 2013), elipsometry (Tress et al., 2010, Inoue et al., 2009, Mok et al., 2010), neutron scattering (Inoue et al., 2009, Soles et al., 2002, Soles et al., 2003, Clough et al., 2011), fluorescence spectroscopy (Connie and John, 2005, Roth et al., 2007, Priestley et al., 2007, Kim et al., 2008), X-ray reflectivity (Wallace et al., 1995, Weber et al., 2001), Brillouin light scattering (Forrest et al., 1997, Mattsson et al., 2000, Fukao et al., 2001), secondary ion mass spectroscopy (Zheng et al., 1997, Pu et al., 2001, Connie and John, 2005) and dielectric spectroscopy (Priestley et al., 2007, Yin et al., 2012, Yin et al., 2013, Tress et al., 2010, Serghei et al., 2005) have been used to interrogate the dynamic behaviour of polymer films of varying thickness on solid support or free-standing. The application of these techniques have, collectively, demonstrated significant decrease in $T_{g}$ with decreasing film thickness below $75 \mathrm{~nm}$ (Connie and John, 2005, Lipson and Milner, 2010). For films analysed on solid support, decreasing the film thickness further to below $20 \mathrm{~nm}$ causes an increase in $T_{g}$ (Yin et al., 2013). The decrease in $T_{g}$ for films $>20$ and $<75 \mathrm{~nm}$ were shown to have no corresponding enhancement in polymer chain mobility and the increase in $T_{g}$ for films $<20 \mathrm{~nm}$ thick were attributed to reduction of segmental mobility due to enhanced interaction between polymer segments and the solid support (Connie and John, 2005, Yin et al., 2013).

Investigation of films at such small thickness scales is important and provides interesting information on mobility of confined polymers, which has important implications in several fields such as microelectronics, optoelectronics, and miniature chemical and biological sensors (Pique et al., 2003, Hojati-Talemi et al., 2013). However, the thickness of pharmaceutical films are typically above $250 \mathrm{~nm}$ (May et al., 2010, May et al., 2011, Zhong et al., 2009) and the 
(C) 2016 This manuscript version is made available under the CC-BY-NC-ND 4.0 license http://creativecommons.org/licenses/by-nc-nd/4.0/

behaviour of confined polymers at thickness $<75 \mathrm{~nm}$ has not been related to the bulk properties of polymer films for pharmaceutical applications. It is therefore equally important to investigate motional behaviour of polymers in bulk films.

The study of thermally stimulated current (TSC) is a useful tool for the characterisation of molecular mobility in polymer films. The technique measures currents generated by the movement of dipoles in response to an externally applied static electrical field (see Appendix A). Due to its low equivalent frequency TSC exhibits greater sensitivity and enhanced resolution of different relaxation processes, when compared with the most commonly used technique i.e. dielectric spectroscopy, for characterising molecular mobility. TSC investigation of formulated polymer films related to intrinsic mobility of polymer molecules within the film is limited and to the authors' knowledge, no such investigation has been performed on hydroxyethyl cellulose (HEC) films.

HEC is a non-ionic cellulose derivative with a broad variety of industrial applications such as in food products, adhesives, paints, textiles and paper (Rahmat et al., 2011, Roy and Rohera, 2002, Luner and Oh, 2001). This cellulose ether derivative has also found wide spread use in pharmaceuticals as controlled release matrix, binders, stabilisers, thickeners and film formers for drug coating and delivery (Kamel et al., 2008). Among the good film forming cellulose ether derivatives, HEC films are perhaps the least investigated and find use only in combination with other polymers (Morales and McConville, 2011). As such the physical behaviour of HEC polymer films has not been fully characterised when compared with other cellulose ether derivatives such as HPC and HPMC. It is therefore necessary to enhance current knowledge of the physical behaviour of HEC films for pharmaceutical applications. In this study, the molecular mobility of HEC films prepared by the solvent casting method has been characterised by means of TSC below the temperature at which the film is formed, as this best represents polymer behaviour within typical pharmaceutical application conditions. 
(C) 2016 This manuscript version is made available under the CC-BY-NC-ND 4.0 license http://creativecommons.org/licenses/by-nc-nd/4.0/

\section{Materials and methods}

\subsection{Materials}

Hydroxyethyl cellulose (average molecular weight $\sim 250 \mathrm{kDa}$, _viscosity of $1 \%$ aqueous solution at $20^{\circ} \mathrm{C}$ is $\sim 145 \mathrm{mPa}$ ) was purchased from Sigma Aldrich (UK).

\subsection{Methods}

\subsubsection{Preparation of films}

Films were prepared using the solvent casting method. Aqueous gel $(2 \% \mathrm{w} / \mathrm{w})$ was prepared by mixing the appropriate amount of HEC in deionised water (heated to $60{ }^{\circ} \mathrm{C}$ ) and the mixture stirred at ambient temperature overnight (18 hours in total). $50 \mathrm{~g}$ of the gel was poured into a plastic Petri dish (diameter of $140 \mathrm{~mm}$ ) and left in a $60{ }^{\circ} \mathrm{C}$ oven for 24 hours. The resultant films were stored in a desiccator over silica for two days before analysing. The films that were optically clear with no visible defects were chosen for analysis (Fig. 1). The thickness of the films were determined using a digital calliper and found to be $0.085 \pm 0.005 \mathrm{~mm}$.

\section{Figure 1 here}

\subsubsection{Thermogravimetric analysis (TGA)}

TGA studies were performed using the Q5000 IR (TA instruments, UK). Sample mass of $3.20 \pm 0.5 \mathrm{mg}$ was used for all compounds. Samples were heated under a nitrogen atmosphere at a flow rate of $25 \mathrm{ml} / \mathrm{min}$ from ambient temperature to $600{ }^{\circ} \mathrm{C}$ in hermetically sealed aluminium pans with a single pin hole in the lid, at a heating rate of $10{ }^{\circ} \mathrm{C} / \mathrm{min}$.

\subsubsection{Differential scanning calorimetry (DSC)}

DSC studies were performed using Q2000 (TA instruments, UK) under a nitrogen atmosphere at a flow of $50 \mathrm{~mL} / \mathrm{min}$, using hermetically sealed Tzero aluminium pans with a pin hole in the 
(C) 2016 This manuscript version is made available under the CC-BY-NC-ND 4.0 license http://creativecommons.org/licenses/by-nc-nd/4.0/

lid. Sample mass of $2.60 \pm 0.24 \mathrm{mg}$ was heated to $140{ }^{\circ} \mathrm{C}$ to remove moisture, equilibrated at $-90{ }^{\circ} \mathrm{C}$, held isothermally for 5 minutes and heated to $200{ }^{\circ} \mathrm{C}$ at $10^{\circ} \mathrm{C} / \mathrm{min}$.

\subsubsection{Texture analysis}

Mechanical (tensile) properties of the HEC films were analysed using a TA HD plus (Stable Micro System, UK) texture analyser. The films $(n=3)$ devoid of any physical defects were cut into dumb-bell shape. A trigger force of $0.1 \mathrm{~N}$ was applied during the testing and the films stretched between two tensile grips at a speed of $0.2 \mathrm{~mm} / \mathrm{s}$ to a maximum distance of $300 \mathrm{~mm}$ or until the films broke. The \% elongation at break, the tensile strength and elastic modulus were determined.

\subsubsection{Thermally stimulated current (TSC) spectroscopy}

TSC studies using the thermally stimulated depolarisation current (TSDC) mode, covering the range -100 to $60{ }^{\circ} \mathrm{C}$ were conducted using a TSCII/RMA spectrometer (SETARAM, France) equipped with a 900 series LN2 (Liquid Nitrogen) micro-dosing cooling system (Norhof, Netherlands) and 6517A electrometer (Keithley, USA). Experiments were performed using electrode arrangement that consists of bottom (13 mm diameter) and upper (10 mm diameter) steel electrodes. The sample diameter cut for analysis was $12.0 \pm 0.5 \mathrm{~mm}$ with an average weight of $14.7 \pm 1 \mathrm{mg}$ and surface area of the sample in direct contact between the top and the bottom electrode was $78.54 \mathrm{~mm}^{2}$. The analysis chamber was evacuated to $10^{-4} \mathrm{mbar}$ and flushed several times with high purity helium (1.1 bars) prior to analysis. Each sample was initially subjected to a pre-treatment in which it was heated to $60{ }^{\circ} \mathrm{C}$ (the film forming temperature) and held isothermal for $30 \mathrm{~min}$. This was followed by evacuation of the analysis chamber to $10^{-4}$ and flushing three times with high purity helium (1.1 bars). The global TSDC spectra were obtained by polarising the sample at $-20{ }^{\circ} \mathrm{C}$ with a polarisation field $\left(\mathrm{E}_{\mathrm{p}}\right)$ ranging from 50 to $300 \mathrm{~V} / \mathrm{mm}$ in increments of $50 \mathrm{~V} / \mathrm{mm}$ for $2 \mathrm{~min}\left(\mathrm{t}_{\mathrm{p}}\right)$. In the case of thermal 
(C) 2016 This manuscript version is made available under the CC-BY-NC-ND 4.0 license

http://creativecommons.org/licenses/by-nc-nd/4.0/

windowing experiments (TW), samples were polarised with $E_{p}=250 \mathrm{~V} / \mathrm{mm}$ at $T_{p}$ of -86 to -8

${ }^{\circ} \mathrm{C}$ in increments of $3{ }^{\circ} \mathrm{C}$. $\mathrm{T}_{\mathrm{w}}$ was set at $3{ }^{\circ} \mathrm{C}$, whilst $\mathrm{t}_{\mathrm{p}}$ and $\mathrm{t}_{\mathrm{w}}$ were set at 2 min for all four samples.

\section{Results and Discussion}

\subsection{Preliminary physical characterization}

Water content determined by TGA (Fig. 2) was found to be $8 \pm 1 \%$ after the dehydration process in the initial heating to $160{ }^{\circ} \mathrm{C}$. The sample was then cooled and reheated to $160{ }^{\circ} \mathrm{C}$ and was found to contain only $0.06 \pm 0.01 \%$ moisture which could be attributed to bound water within the polymeric film matrix. DSC analysis (Fig. 3) showed a single glass transition temperature at $127 \pm 1{ }^{\circ} \mathrm{C}$, followed by degradation of the polymer at $\sim 180{ }^{\circ} \mathrm{C}$. The $T_{g}$ determined for the HEC films is in agreement with previously reported data (Kararli et al., 1990). The results obtained from texture analysis show the solvent cast HEC film undergo $9 \%$ elongation at break, with tensile strength of $10 \pm 3 \mathrm{Nmm}^{2}$ and elastic modulus of $115 \pm 1 \mathrm{mPa}$.

\section{Figure 2 here}

\section{Figure 3 here}

\subsection{TSDC}

TSDC experiments were initially performed at various poling temperatures (from -80 to $50{ }^{\circ} \mathrm{C}$ ) to identify the temperature region where samples display observable and reproducible depolarisation currents. The TSDC outputs showed that HEC films undergo a global relaxation process with a small shoulder on the high temperature side, prior to the film forming temperature $\left(60{ }^{\circ} \mathrm{C}\right)$ (Fig. 4). This global relaxation process, which has a temperature maxima $\left(\mathrm{T}_{M}\right)$ at $-22 \pm 1{ }^{\circ} \mathrm{C}$, is confirmed to originate from molecular dipole orientations, intrinsic to molecules in the HEC film i.e. there is a linear relationship $\left(\mathrm{R}^{2}=0.9998\right)$ between the ratios of 
(C) 2016 This manuscript version is made available under the CC-BY-NC-ND 4.0 license http://creativecommons.org/licenses/by-nc-nd/4.0/

total polarisation $(\mathrm{P})$ and that of the applied electrical field strength $\left(\mathrm{E}_{\mathrm{p}}\right)$, with a slope very close to unity and an intercept at 0 (Fig. 5) (Correia et al., 2000, Diogo et al., 2008, Pinto et al., 2010). Furthermore this relaxation process was detected at the same temperature even after the sample was dehydrated, which proves that it originates from the movement of HEC molecules within the film with negligible or no contribution from water molecules. The increasingly high current tail observed above $25^{\circ} \mathrm{C}$ is likely to originate from a combination of polymer mobility and movement of water molecules (which may indicate the initial molecular motions that contribute to the evaporation process at higher temperatures).

\section{Fig. 4 about here}

\section{Fig. 5 about here}

The individual relaxation processes contributing to the global TSDC process were deconvoluted by means of thermal windowing (TW) experiments (Fig. 6). These results show more clearly the existence of two groups of relaxation processes with peak maxima located at $-22 \pm 1{ }^{\circ} \mathrm{C}$ and $0 \pm 1{ }^{\circ} \mathrm{C}$. Furthermore, Fig. 6 (insert) shows the distribution of relaxation times (Bucci lines) for the first twelve isolated relaxation processes to exhibit straight lines, while a small degree of curvature was observed for rest of the isolated relaxation processes. This indicates that up to the twelfth isolated processes $\left(\mathrm{T}_{\mathrm{p}}=-53{ }^{\circ} \mathrm{C}\right)$, the activation energies of molecular relaxations are narrowly distributed (Alvarez et al., 2000, Correia et al., 2000) and implies the movement of a single molecular fragment for each isolated relaxation process. At polarisation temperatures above $-53{ }^{\circ} \mathrm{C}$, Bucci line curvature observed suggests the activation energies are no longer narrowly distributed, therefore two or more groups of molecular fragments with different activation energies are activated in each isolated relaxation process. These observations demonstrate that a number of motional modes are activated in HEC films well below ambient temperatures with an average relaxation time of $50 \pm 3 \mathrm{~s}$. 
(C) 2016 This manuscript version is made available under the CC-BY-NC-ND 4.0 license

http://creativecommons.org/licenses/by-nc-nd/4.0/

\section{Fig. 6 about here}

The cooperative nature of these isolated relaxation processes were investigated further using the enthalpy of activation ( $\Delta H^{*}$ ) (extracted by means of the Eyring's model) in a Starkweather type analysis (Ramos and Mano, 1997) (Fig. 7). In this analysis the assumption is made that $\Delta H^{*}$ values have no entropic contribution $\left(\Delta S^{*}=0\right)$ when the relaxation process is noncooperative, whilst for cooperative relaxation processes, the $\Delta H^{*}$ values has entropic contribution $\left(\Delta S^{*} \neq 0\right)$ and will therefore deviate from the zero entropy prediction. The $\Delta H^{*}$ values for the first twelve isolated relaxations processes (first twelve points) are close to the zero entropy prediction and are therefore non-cooperative. The group of non-cooperative relaxations are secondary, $\beta$-relaxations, with the temperature located at $-57 \pm 2{ }^{\circ} \mathrm{C}$. This $\beta$ relaxation is proposed to originate from localised orientation of short sections of the HEC polymer chain ends and/or the hydroxyethyl side groups.

Relaxation processes activated above $-53{ }^{\circ} \mathrm{C}$ (points 13 to 27 in Fig. 7) deviated from the zero entropy line and are therefore cooperative i.e. they require the cooperation of neighbouring atoms, molecules or molecular segments to move. The rise and descent of the $\Delta H^{\ddagger}$ values represent the beginning and end of a transition (Sauer and Avakian, 1992, Sauer et al., 1996), hence points 13 to 23 (Fig. 4) are considered an $\alpha$-relaxation. Points 24 to 27 represents the beginning of a second cooperative relaxation processes that is related to other higher temperature processes.

\section{Fig. 7 about here}

Cooperative mobility or $\alpha$-relaxations are associated with the glass transition process (Smith and Bedrov, 2007). The fact that this $\alpha$-relaxation (Tm' $=-20 \pm 2{ }^{\circ} \mathrm{C}$ ) was not detected by DSC suggests it is of low energy and likely to originate from mobility of a small group of HEC polymer segments (smaller group(s) of polymer segments in comparison to the size and number 
(C) 2016 This manuscript version is made available under the CC-BY-NC-ND 4.0 license http://creativecommons.org/licenses/by-nc-nd/4.0/

of polymer segments that would typically generate heat signal large enough to be detected by DSC for bulk glass transitions) in localised regions of the film. The solvent cast HEC film, therefore has two amorphous regions with different glass transition temperatures; a local glass transition at $-20 \pm 2{ }^{\circ} \mathrm{C}$ (determined by TSC) and the bulk glass transition at $127 \pm 1{ }^{\circ} \mathrm{C}$ (detected by DSC).

The results obtained from texture analysis indicate that the film is brittle and hard (Felton and Porter, 2013, Felton et al.). From the TSC analysis it was observed that the HEC film undergoes $\beta$-relaxation as-well-as local $\alpha$-relaxation processes (local glass transition). These molecular motions are of small scale, involving only a small group of short sections of HEC polymer molecules within the film. Therefore at the temperature of testing $\left(22 \pm 2{ }^{\circ} \mathrm{C}\right) \mathrm{using}$ texture analysis, molecules within the film do not have enough motional freedom/ orientational capacity to plastically deform under tensile stress before failure. This explains the very low $\%$ elongation at break of $9 \%$. Due to the high average molecular weight $(\sim 250 \mathrm{kDa})$ of the HEC, polymer used is able to undergo high degree of intermolecular and intramolecular interactions through hydrogen bonding. Such high degree of interaction in the HEC film limits the ability of molecules to undergo large scale mobility, making the film brittle and rigid, resulting in the high tensile strength and elastic modulus respectively. Such low flexibility could also be due in part to the absence of plasticiser and the low residual moisture content below $10 \%$.

The current study potentially has important pharmaceutical technology implications for film based formulations. Generally, films have low drug loading due to the reduced physical volume as a result of the thin nature and therefore effect of such low drug loadings at the molecular level is not always detectable using the traditional thermal techniques such as DSC. Therefore, detection of molecular motions using the more sensitive TSC provides an extra capability in characterising the functional performance of pharmaceutical films. It is also plausible that the 
(C) 2016 This manuscript version is made available under the CC-BY-NC-ND 4.0 license

http://creativecommons.org/licenses/by-nc-nd/4.0/

information gained from such investigations might provide complimentary information about physico-chemical stability in the apparently dry state of pharmaceutical films which always have residual levels of bound water.

\section{Conclusions}

Molecular mobility can have significant influence on the stability and textural properties of polymeric films. The application of TSC has revealed two motional processes, a $\beta$ - and $\alpha$ relaxations, well below ambient temperatures in solvent casted HEC film. The non-cooperative $\beta$-relaxation, detected at $-57 \pm 2{ }^{\circ} \mathrm{C}$ originates from independent orientation of short sections of the HEC polymer chain ends and the hydroxyethyl side groups. The $\alpha$-relaxation detected at $-20 \pm 2{ }^{\circ} \mathrm{C}$, which could not be detected by DSC, is attributed to cooperative mobility involving a small group of short HEC polymer segments and considered a local glass transition process. The fact that this $\alpha$-relaxation $\left(\mathrm{Tm}^{\prime}=-20 \pm 2{ }^{\circ} \mathrm{C}\right.$ ) was not detected by DSC suggests it is of low energy and likely to originate from mobility of a small group of HEC polymer segments in localised regions of the film and has energy signature lower than the detection limit of conventional DSC.

The bulk $T_{g}$ of the solvent cast HEC polymer film was detected at $127 \pm 1{ }^{\circ} \mathrm{C}$ and it can be concluded that the HEC film investigated has two amorphous regions with different motional properties. Together with texture analysis data, this study has demonstrated that the brittle and rigid nature of the solvent cast $\mathrm{HEC}(\sim 250 \mathrm{kDa})$ film at the temperature studied is attributed to the fact that it can only undergo small scale, localised and low energy molecular motions. This limited orientational capacity of HEC polymers in the film matrix is the direct result of the size of the polymer and the high degree of strong intra and intermolecular hydrogen bonding it undergoes within the film.

\section{Acknowledgement}


(C) 2016 This manuscript version is made available under the CC-BY-NC-ND 4.0 license http://creativecommons.org/licenses/by-nc-nd/4.0/

This study was funded by the University of Greenwich. Samuel K. Owusu-Ware wishes to thank the University of Greenwich for funding Post-Doctoral research.

\section{References}

ALVAREZ, C., CORREIA, N. T., RAMOS, J. J. M. \& FERNANDES, A. C. 2000. Glass transition relaxation and fragility in a side-chain liquid crystalline polymer: a study by TSDC and DSC. Polymer, 41, 29072914.

BALA, R., PAWAR, P., KHANNA, S. \& ARORA, S. 2013. Orally dissolving strips: A new approach to oral drug delivery system. International Journal of Pharmaceutical Investigation, 3, 67-76.

BALLESTEROS, D. \& WALTERS, C. 2011. Detailed characterization of mechanical properties and molecular mobility within dry seed glasses: relevance to the physiology of dry biological systems. Plant Journal, 68, 607-619.

BHATTACHARJYA, S. \& WURSTER, D. 2008. Investigation of the Drug Release and Surface Morphological Properties of Film-Coated Pellets, and Physical, Thermal and Mechanical Properties of Free Films as a Function of Various Curing Conditions. AAPS PharmSciTech, 9, 449-457.

BHUGRA, C., SHMEIS, R., KRILL, S. L. \& PIKAL, M. J. 2008. Different measures of molecular mobility: Comparison between calorimetric and thermally stimulated current relaxation times below $\mathrm{Tg}$ and correlation with dielectric relaxation times above Tg. Journal of Pharmaceutical Sciences, 97, 4498-4515. 
(C) 2016 This manuscript version is made available under the CC-BY-NC-ND 4.0 license http://creativecommons.org/licenses/by-nc-nd/4.0/

CLOUGH, A., PENG, D. D., YANG, Z. H. \& TSUI, O. K. C. 2011. Glass Transition Temperature of Polymer Films That Slip. Macromolecules, 44, 1649-1653.

CONNIE, B. R. \& JOHN, R. D. 2005. Mobility on Different Length Scales in Thin Polymer Films. In: DUTCHER, J. R. \& MARANGONI, A. G. (eds.) Soft Materials: Structure and Dynamics. New York: Marcel Dekker.

CORREIA, N. T., ALVAREZ, C., RAMOS, J. J. M. \& DESCAMPS, M. 2000. Molecular motions in molecular glasses as studied by thermally stimulated depolarization currents (TSDC). Chemical Physics, $252,151-163$.

DAMACEANU, M. D., RUSU, R. D., CRISTEA, M., MUSTEATA, V. E., BRUMA, M. \& WOLINSKAGRABCZYK, A. 2014. Insights into the Chain and Local Mobility of Some Aromatic Polyamides and Their Influence on the Physicochemical Properties. Macromolecular Chemistry and Physics, 215, 1573-1587.

DIOGO, H. P., PINTO, S. S. \& MOURA RAMOS, J. J. 2008. Relaxation behaviour of d(-)-salicin as studied by Thermally Stimulated Depolarisation Currents (TSDC) and Differential Scanning Calorimetry (DSC). International Journal of Pharmaceutics, 358, 192-197.

FADDA, H. M., KHANNA, M., SANTOS, J. C., OSMAN, D., GAISFORD, S. \& BASIT, A. W. 2010. The use of dynamic mechanical analysis (DMA) to evaluate plasticization of acrylic polymer films under simulated gastrointestinal conditions. European Journal of Pharmaceutics and Biopharmaceutics, 76, 493-497.

FELTON, L. A. 2007. Characterization of coating systems. AAPS PharmSciTech, 8, 258-266.

FELTON, L. A., O'DONNELL, P. B. \& MCGINITY, J. W. Mechanical Properties of Polymeric Films Prepared from Aqueous Dispersions. Aqueous Polymeric Coatings for Pharmaceutical Dosage Forms.

FELTON, L. A. \& PORTER, S. C. 2013. An update on pharmaceutical film coating for drug delivery. Expert Opinion on Drug Delivery, 10, 421-435. 
(C) 2016 This manuscript version is made available under the CC-BY-NC-ND 4.0 license http://creativecommons.org/licenses/by-nc-nd/4.0/

FORREST, J. A., DALNOKIVERESS, K. \& DUTCHER, J. R. 1997. Interface and chain confinement effects on the glass transition temperature of thin polymer films. Physical Review E, 56, 5705-5716.

FUKAO, K., UNO, S., MIYAMOTO, Y., HOSHINO, A. \& MIYAJI, H. 2001. Dynamics of alpha and beta processes in thin polymer films: Poly(vinyl acetate) and poly(methyl methacrylate). Physical Review E, 64.

HOJATI-TALEMI, P., BAECHLER, C., FABRETTO, M., MURPHY, P. \& EVANS, D. 2013. Ultrathin Polymer Films for Transparent Electrode Applications Prepared by Controlled Nucleation. Acs Applied Materials \& Interfaces, 5, 11654-11660.

INOUE, R., KANAYA, T., NISHIDA, K., TSUKUSHI, I., TELLING, M. T. F., GABRYS, B. J., TYAGI, M., SOLES, C. \& WU, W. L. 2009. Glass transition and molecular mobility in polymer thin films. Physical Review E, 80, 031802.

KAMEL, S., ALI, N., JAHANGIR, K., SHAH, S. M. \& EL-GENDY, A. A. 2008. Pharmaceutical significance of cellulose: A review. Express Polymer Letters, 2, 758-778.

KARARLI, T. T., HURLBUT, J. B. \& NEEDHAM, T. E. 1990. GLASS RUBBER TRANSITIONS OF CELLULOSIC POLYMERS BY DYNAMIC MECHANICAL ANALYSIS. Journal of Pharmaceutical Sciences, 79, $845-848$.

KIM, J., SANDOVAL, R. W., DETTMER, C. M., NGUYEN, S. T. \& TORKELSON, J. M. 2008. Compatibilized polymer blends with nanoscale or sub-micron dispersed phases achieved by hydrogenbonding effects: Block copolymer vs blocky gradient copolymer addition. Polymer, 49, 26862697.

LIPSON, J. E. G. \& MILNER, S. T. 2010. Local and Average Glass Transitions in Polymer Thin Films. Macromolecules, 43, 9874-9880.

LUNER, P. E. \& OH, E. 2001. Characterization of the surface free energy of cellulose ether films. Colloids and Surfaces a-Physicochemical and Engineering Aspects, 181, 31-48.

MATTSSON, J., FORREST, J. A. \& BORJESSON, L. 2000. Quantifying glass transition behavior in ultrathin free-standing polymer films. Physical Review E, 62, 5187-5200. 
(C) 2016 This manuscript version is made available under the CC-BY-NC-ND 4.0 license http://creativecommons.org/licenses/by-nc-nd/4.0/

MAY, R. K., EVANS, M. J., ZHONG, S. C., WARR, I., GLADDEN, L. F., SHEN, Y. C. \& ZEITLER, J. A. 2011. Terahertz In-Line Sensor for Direct Coating Thickness Measurement of Individual Tablets During Film Coating in Real-Time. Journal of Pharmaceutical Sciences, 100, 1535-1544.

MAY, R. K., EVANS, M. J., ZHONG, S. C., WARR, I., GLADDEN, L. F., SHEN, Y. C., ZEITLER, J. A. \& IEEE 2010. In-Line Monitoring of Coating Thickness of Pharmaceutical Tablets during Production Scale Film Coating by Terahertz Imaging. 35th International Conference on Infrared, Millimeter, and Terahertz Waves (Irmmw-Thz 2010).

MCPHILLIPS, H., CRAIG, D. Q. M., ROYALL, P. G. \& HILL, V. L. 1999. Characterisation of the glass transition of HPMC using modulated temperature differential scanning calorimetry. International Journal of Pharmaceutics, 180, 83-90.

MOK, M. M., KIM, J., MARROU, S. R. \& TORKELSON, J. M. 2010. Ellipsometry measurements of glass transition breadth in bulk films of random, block, and gradient copolymers. European Physical Journal E, 31, 239-252.

MORALES, J. O. \& MCCONVILLE, J. T. 2011. Manufacture and characterization of mucoadhesive buccal films. European Journal of Pharmaceutics and Biopharmaceutics, 77, 187-199.

PINTO, S. S., DIOGO, H. P., NUNES, T. G. \& MOURA RAMOS, J. J. 2010. Molecular mobility studies on the amorphous state of disaccharides. I--thermally stimulated currents and differential scanning calorimetry. Carbohydrate Research, 345, 1802-1807.

PIQUE, A., AUYEUNG, R. C. Y., STEPNOWSKI, J. L., WEIR, D. W., ARNOLD, C. B., MCGILL, R. A. \& CHRISEY, D. B. 2003. Laser processing of polymer thin films for chemical sensor applications. Surface \& Coatings Technology, 163, 293-299.

PRIESTLEY, R. D., RITTIGSTEIN, P., BROADBELT, L. J., FUKAO, K. \& TORKELSON, J. M. 2007. Evidence for the molecular-scale origin of the suppression of physical ageing in confined polymer: fluorescence and dielectric spectroscopy studies of polymer-silica nanocomposites. Journal of Physics-Condensed Matter, 19. 
(C) 2016 This manuscript version is made available under the CC-BY-NC-ND 4.0 license http://creativecommons.org/licenses/by-nc-nd/4.0/

PU, Y., RAFAILOVICH, M. H., SOKOLOV, J., GERSAPPE, D., PETERSON, T., WU, W. L. \& SCHWARZ, S. A. 2001. Mobility of polymer chains confined at a free surface. Physical Review Letters, 87.

RAHMAT, D., SAKLOETSAKUN, D., SHAHNAZ, G., PERERA, G., KAINDL, R. \& BERNKOP-SCHNUERCH, A. 2011. Design and synthesis of a novel cationic thiolated polymer. International Journal of Pharmaceutics, 411, 10-17.

RAMOS, J. J. M. \& MANO, J. F. 1997. Some comments on the significance of the compensation effect observed in thermally stimulated current experiments. Polymer, 38, 1081-1089.

ROTH, C. B., MCNERNY, K. L., JAGER, W. F. \& TORKELSON, J. M. 2007. Eliminating the enhanced mobility at the free surface of polystyrene: Fluorescence studies of the glass transition temperature in thin bilayer films of immiscible polymers. Macromolecules, 40, 2568-2574.

ROY, D. S. \& ROHERA, B. D. 2002. Comparative evaluation of rate of hydration and matrix erosion of HEC and HPC and study of drug release from their matrices. European Journal of Pharmaceutical Sciences, 16, 193-199.

SAUER, B. B. \& AVAKIAN, P. 1992. Cooperative relaxations in amorphous polymers studied by thermally stimulated current depolarization. Polymer, 33, 5128-5142.

SAUER, B. B., AVAKIAN, P. \& STARKWEATHER, H. W. 1996. Cooperative Relaxations in Semicrystalline Fluoropolymers Studied by Thermally Stimullated Currents and ac Dielectric. Journal of Polymer Science: Part B, 34, 517-528.

SERGHEI, A., MIKHAILOVA, Y., HUTH, H., SCHICK, C., EICHHORN, K. J., VOIT, B. \& KREMER, F. 2005. Molecular dynamics of hyperbranched polyesters in the confinement of thin films. European Physical Journal E, 17, 199-202.

SMITH, G. D. \& BEDROV, D. 2007. Relationship between the $\alpha$ - and $\beta$-relaxation processes in amorphous polymers: Insight from atomistic molecular dynamics simulations of 1,4polybutadiene melts and blends. Journal of Polymer Science Part B: Polymer Physics, 45, 627643. 
(C) 2016 This manuscript version is made available under the CC-BY-NC-ND 4.0 license http://creativecommons.org/licenses/by-nc-nd/4.0/

SOLES, C. L., DOUGLAS, J. F., WU, W. L. \& DIMEO, R. M. 2002. Incoherent neutron scattering and the dynamics of confined polycarbonate films. Physical Review Letters, 88.

SOLES, C. L., DOUGLAS, J. F., WU, W. L. \& DIMEO, R. M. 2003. Incoherent neutron scattering as a probe of the dynamics in molecularly thin polymer films. Macromolecules, 36, 373-379.

TRESS, M., ERBER, M., MAPESA, E. U., HUTH, H., MULlER, J., SERGHEI, A., SCHICK, C., EICHHORN, K. J., VOLT, B. \& KREMER, F. 2010. Glassy Dynamics and Glass Transition in Nanometric Thin Layers of Polystyrene. Macromolecules, 43, 9937-9944.

WALLACE, W. E., VANZANTEN, J. H. \& WU, W. L. 1995. INFLUENCE OF AN IMPENETRABLE INTERFACE ON A POLYMER GLASS-TRANSITION TEMPERATURE. Physical Review E, 52, R3329-R3332.

WANG, J. H. \& MCKENNA, G. B. 2013. Viscoelastic and Glass Transition Properties of Ultrathin Polystyrene Films by Dewetting from Liquid Glycerol. Macromolecules, 46, 2485-2495.

WEBER, R., ZIMMERMANN, K. M., TOLAN, M., STETTNER, J., PRESS, W., SEECK, O. H., ERICHSEN, J., ZAPOROJTCHENKO, V., STRUNSKUS, T. \& FAUPEL, F. 2001. X-ray reflectivity study on the surface and bulk glass transition of polystyrene. Physical Review E, 64 .

YIN, H., CANGIALOSI, D. \& SCHONHALS, A. 2013. Glass transition and segmental dynamics in thin supported polystyrene films: The role of molecular weight and annealing. Thermochimica Acta, 566, 186-192.

YIN, H. J., NAPOLITANO, S. \& SCHONHALS, A. 2012. Molecular Mobility and Glass Transition of Thin Films of Poly(bisphenol A carbonate). Macromolecules, 45, 1652-1662.

ZHANG, C., BOUCHER, V. M., CANGIALOSI, D. \& PRIESTLEY, R. D. 2013. Mobility and glass transition temperature of polymer nanospheres. Polymer, 54, 230-235.

ZHENG, X., RAFAILOVICH, M. H., SOKOLOV, J., STRZHEMECHNY, Y., SCHWARZ, S. A., SAUER, B. B. \& RUBINSTEIN, M. 1997. Long-range effects on polymer diffusion induced by a bounding interface. Physical Review Letters, 79, 241-244.

ZHONG, S. C., SHEN, Y. C., EVANS, M., ZEITLER, J. A., MAY, R. K., GLADDEN, L. F., BYERS, C. \& IEEE 2009. Quantification of Thin-film Coating Thickness of Pharmaceutical Tablets using Wavelet 
(C) 2016 This manuscript version is made available under the CC-BY-NC-ND 4.0 license

http://creativecommons.org/licenses/by-nc-nd/4.0/

Analysis of Terahertz Pulsed Imaging Data. 2009 34th International Conference on Infrared,

Millimeter, and Terahertz Waves, Vols 1 and 2, 47-48.

\section{Figure Legends}

Fig. 1 Typical example of the HEC films used for studies exhibiting transparency with no visually observable defects (e.g. patches, tears or cracks).

Fig. 2 A typical TGA output for HEC film showing the first and second heating cycles.

Fig. 3 DSC thermograms of HEC films obtained using TA Instruments (UK) Q2000 DSC. Each sample is initially heated from -90 to $140{ }^{\circ} \mathrm{C}$ at $10{ }^{\circ} \mathrm{C} / \mathrm{min}$ to remove moisture (not shown), cooled and heated a second time from -90 to $140{ }^{\circ} \mathrm{C}$ at $10{ }^{\circ} \mathrm{C} / \mathrm{min}$.

Fig. 4 TSDC signals obtained for HEC film at different polarisation temperatures using a field strength of $100 \mathrm{~V} / \mathrm{mm}$. The insert is a zoomed-in area of the TSDC process of interest.

Fig. 5 Global TSDC curve overlay of HEC film polarised at $-20{ }^{\circ} \mathrm{C}$ using electrical field strength $\left(E_{p}\right)$ of $50-300 \mathrm{~V} / \mathrm{mm}$ with an insert of a linear regression showing the relationship between the ratios of total polarisation and the ratios of $\mathrm{E}_{\mathrm{p}}$ applied. $\mathrm{P}\left(\mathrm{E}_{\mathrm{p}}\right)$ is the polarisation obtained at a particular Ep and $\mathrm{P}\left(\mathrm{E}_{\mathrm{p}}{ }^{0}\right)$ is the polarisation obtained for the lowest $\mathrm{E}_{\mathrm{p}}$.

Fig. 6 Typical TW results obtained for HEC films showing the isolated motional modes along with the corresponding distribution of relaxation times/ Bucci lines (insert) detected for below the film forming temperature. 
(C) 2016 This manuscript version is made available under the CC-BY-NC-ND 4.0 license http://creativecommons.org/licenses/by-nc-nd/4.0/

Fig. 7 Overlay of the plots of the enthalpy of activation $\left(\Delta H^{*}\right)$ values obtained for each isolated relaxation process from thermal windowing (TW) experiments and the zero entropy prediction $(\Delta S=0)$. 